\title{
Semantics-Enhanced E-Learning Courses
}

\author{
Steffen Mencke and Reiner Dumke \\ Otto-von-Guericke University Magdeburg \\ Germany
}

\section{Introduction}

The provision of information and expertise was always a primary task of computersupported learning systems. In the days of the overwhelming data and information burst of the 21st century, new and innovative handling approaches are necessary. With every single day, the importance of the statement of John Naisbitt increases, who once said that the human mankind is drowning in information, but starving for knowledge.

Because of this, new and improved mechanisms are necessary to adequately provide eLearning content. Semantic Web technologies, especially ontologies, are seen as the key approach with tremendous potential to future applications (Hendler, 2008).

After a short introduction to these technologies, this chapter will propose new solutions for an ontology-based e-Learning content provision.

\section{Semantic Web}

Semantics (from the Greek word semantikos = significant) in general is the meaning of something or more specifically the study of meaning (Encyclopædia Britannica - Online, 2008). Often, additional information is needed to shift from information processing to knowledge processing. Those semantic annotations provide the technological basis for many advanced applications. Semantic support is needed for different reasons, e.g.:

- To make the Web (and other information providing systems) more machineunderstandable (Heflin and Hendler, 2001)

- To provide an infrastructure for intelligent agents (Hendler, 2001); (Cost et al., 2002)

- To explicitly declare knowledge for access, integration and extraction purposes (Gómez-Pérez and Corcho, 2002)

- To support automation, integration and reuse across applications and domains (Boley et al., 2001)

- To make Web Services computer interpretable (Narayanan and McIlrath, 2001)

The realization of annotations ranges from simple metadata to the definition of semantics in the vision of a Semantic Web (Antoniou and van Harmelen, 2004). 


\subsection{Core Idea}

The Semantic Web is no alternative to the current World Wide Web, but a logic extension. The machine-accessibility, as envisioned by Berners-Lee (Berners-Lee et al., 2001), as well as the implementation of metadata within and about the Web are necessary. They are a next step following the already outlined structured description of content.

In (Daconta et al., 2003) four different levels of data handling towards the Semantic Web are described.

- Text and Databases: Such data sets are application-specific. The automated usage is not always intended and automatic reasoning is rarely possible.

- XML documents of a certain domain: Thereby, application independence can be achieved for a special domain. Vertical XML standards support data exchange between applications of the same domain.

- Taxonomies and documents with several standards: Data representations with taxonomies and multiple standards support the easy search and combination of data.

- Ontologies and rules: Ontologies and rules basing on them, allow the extraction of new knowledge based on existing data by logic reasoning. The data is atomically described with its relationships.

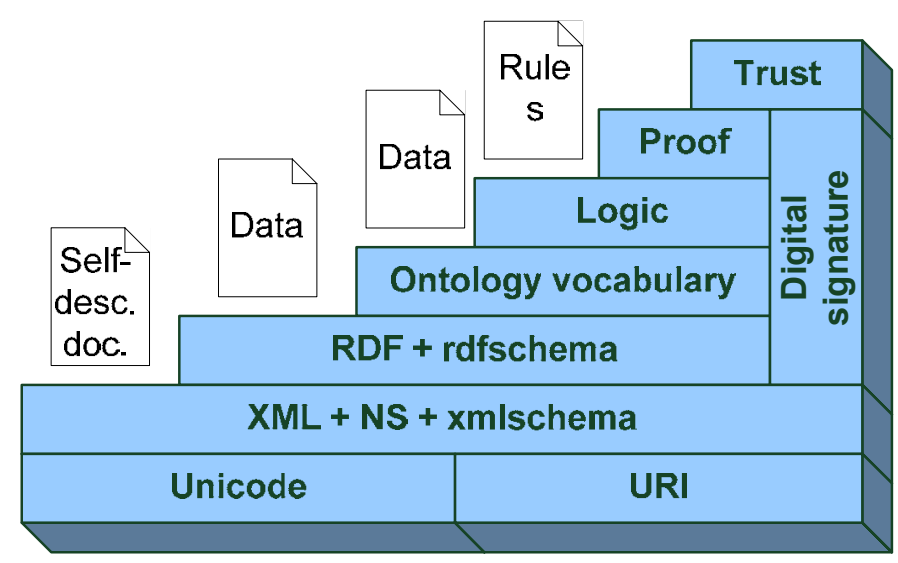

Fig. 1. A Layered Approach to the Semantic Web (Berners-Lee et al., 2001)

Figure 1 shows the layers of the Semantic Web design and vision according to Tim BernersLee. Every layer provides the necessary functionality for the layers above. XML is used to basically encode documents and RDF to define simple statements about the resource. They form the basis for more powerful ontology languages for more complex relationships. On the logic layer additional information can be defined to write application-specific declarative knowledge. The representation of proofs and proof validation can be performed on the proof layer involving a deductive process. The trust layer on top introduces trust for agents, agencies and consumers by defining digital signatures and other kinds of knowledge (Antoniou and van Harmelen, 2004). 


\subsection{Ontologies}

Ontologies are a fundamental concept of the Semantic Web. The word ontology is originally Greek: ontos for being and logos for word (Devedžić, 2006). It is the study of the categories of things within a domain (Sowa, 2000). Together with explicit representations of the semantics of data for machine-accessibility, such domain theories are the basis for intelligent next generation applications for the Web and other areas of interest (Devedžić, 2006) with a special focus on knowledge sharing and reuse. Furthermore they define, e.g.:

- A vocabulary for the unambiguous meaning (Chandrasekaran et al., 1999)

- A taxonomy for classification of entities (Devedžić, 2006)

- Content theory, due to the definition of classes of objects, relations and concept hierarchies (Chandrasekaran et al., 1999)

- Enabling consistency checking (Devedžić, 2006)

Top-level application areas identified by (Fikes, 1998) are collaboration, interoperability, education and modelling. Application domains are not limited, too. Ontologies are useful, wherever semantic information can enhance certain tools, products or processes (e.g. eLearning ((Devedžić, 2006); (Mencke and Dumke, 2007b)), Virtual Engineering (Vornholt and Mencke, 2008) ...).

Based on the definition by (Gruber, 1993), ontologies are defined as a specification of a conceptualization. Or in other words: they are the formal representation of an abstract view of the world. They include a vocabulary, taxonomy, instances, attributes, relations and axioms about a certain domain.

A vocabulary defines terms with unambiguous meanings. Furthermore, logical statements for the description of terms and rules for their combination and relation are provided. A taxonomy is part of the ontology concept for a hierarchical classification in a machineprocessable form. Individuals/instances represent the objects of the ontology and thereby the available knowledge, while classes/concepts describe abstract sets of individuals. Attributes can be assigned to instances for description. They have a name and value. The last key element of ontologies is the relation. It can be described by using attributes and assigning another individual as a value. Common relation types are the is-a relation (subsumption relation) and the part-of relation (meronymy relation). The possibility to define domain-specific relations is a considerable additional value of the concept of an ontology. Axioms are always true and represent knowledge that is not inferable from other individuals.

It is possible to distinguish ontologies in two broad categories: lightweight and heavyweight ontologies. A lightweight ontology is described by individuals, classes, attributes, relations and axioms, meanwhile heavyweight ontologies are an extension of lightweight ones by the additional usage of axioms for a more detailed domain description.

Technologies for semantic annotations differ in their semantic expressiveness. Figure 2 shows the ontology spectrum following (Daconta et al., 2003). Complex tasks within the Semantic Web require standards for the representation of data and metadata. The most important standards are the Resource Description Framework (RDF) and its extensions like the DARPA Agent Markup Language (DAML) + Ontology Inference Layer (OIL) and the Web Ontology Language (OWL). 


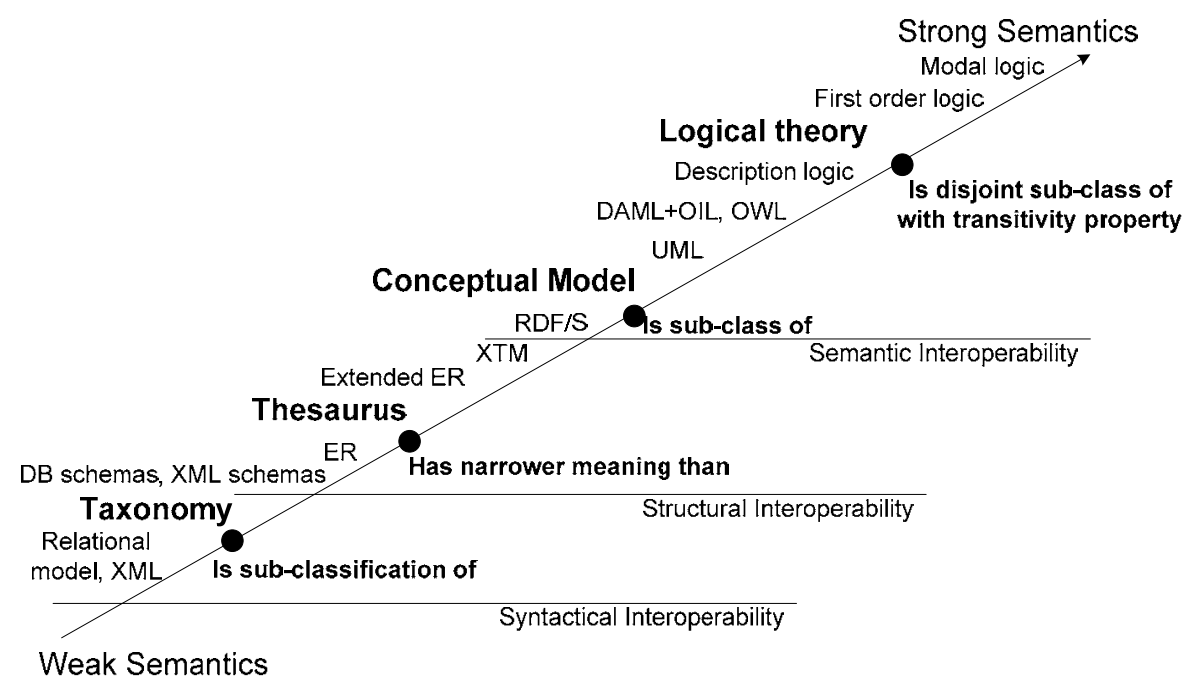

Fig. 2. The Ontology-Spectrum: Weak to Strong Semantics (following (Daconta et al., 2003))

\subsection{Web Ontology Language}

The Web Ontology Language is an XML-based ontology language. It was developed by the W3C to replace the DARPA Agent Markup Language and Ontology Inference Layer (DAML+OIL), another - already deprecated - ontology language ((Cost et al., 2002]); (Daconta et al., 2003); (Devedžić, 2006)). Additional information about DAML+OIL as well their root ontology languages DAML-ONT and OIL can be found e.g. in (Hendler and McGuinness, 2000) as well as (Fensel et al., 2001).

OWL bases on the Resource Description Framework - a language to describe data about entities in terms of object-attribute-value triplets. Every RDF resource is a list of such triplets, also called statements. Thereby, the object is a Web resource, the attribute one of its properties and the value a literal or other resource (World Wide Web Consortium (W3C), 2004a). As being part of the layered Semantic Web approach (shown in Figure 1), RDF uses XML syntax.

OWL can be seen as a set of RDF-triples of an OWL-specific vocabulary with an OWLspecific meaning (World Wide Web Consortium (W3C), 2004b). OWL consists of three levels. The easier ones are completely part of the more complex ones:

- OWL Full: Is a complete OWL-language. For example, a class can be a set of individuals as well as an individual itself.

- OWL DL (Description Logic): OWL DL is a limited OWL. Here, e.g. classes cannot be individuals. It is possible to use more expressive cardinalities.

- OWL Lite: It is the simplest OWL language. Here, only simple cardinalities are possible.

Already OWL Lite is capable to define an ontology of classes, attributes as well as instances of these classes and attributes. OWL DL extends this expressiveness by the possibility of more powerful cardinalities being not limited to only 0 or 1 . Furthermore, the creation of 
classes with boolean operators and lists is possible. OWL Full represents the complete capabilities of all OWL language layers. Classes for example, can be interpreted as sets as well as an individual (Daconta et al., 2003).

An example is given in Figure 3 (graphical representation) and Figure 4 (XML-based representation).

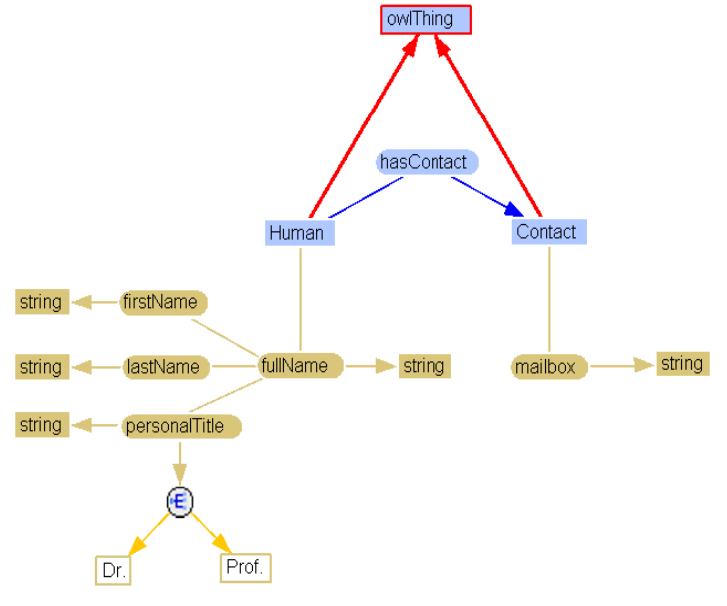

Fig. 3. Graphical Representation of an OWL Example

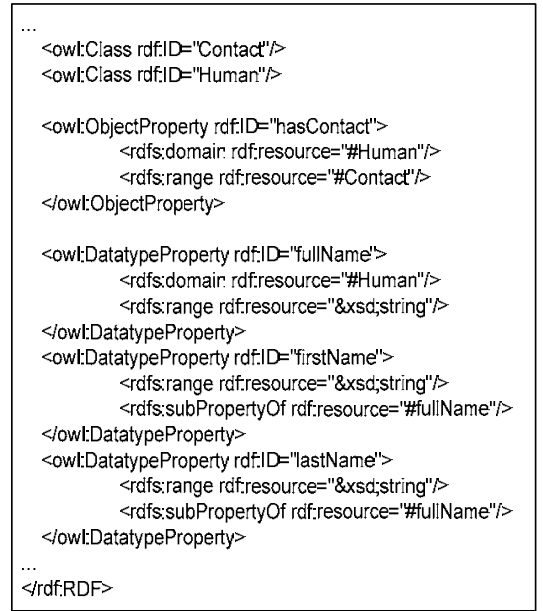

Fig. 4. XML-Based Representation of an OWL Example

\section{E-Learning and E-Learning Content Assembly}

Especially e-Learning is nowadays one of the most interesting of the "e-"domains available through the Internet (Anghel and Salomie, 2003). In general, it refers to a wide range of applications and processes designed to deliver instruction through computational means (Juneidi and Vouros, 2005). It is seen as a technology-based learning alternative respectively extension to the classic classroom model (Giotopoulos et al., 2005).

\subsection{E-Learning}

Following the American Society for Training \& Development (ASTD), e-Learning is the electronic support of learning processes and covers a wide set of applications and processes, such as Web-based learning, computer-based learning, virtual classrooms, and digital collaboration (American Society for Training \& Development (ASTD), 2008).

E-Learning is not intended to exclude existing methods and technologies. An appropriate use might complement them (Anghel and Salomie, 2003), e.g. as Blended Learning where eLearning and traditional presence learning are merged (Schmietendorf and Mencke, 2008). Current technical and technological progress and development lead to an increased usage of collaborative environments and distributed learning techniques. Nevertheless, it bases on classic learning theories and complements well established learning and teaching approaches. 
A general view on e-Learning systems, involved roles and components is visualized in Figure 5. Technically, it can be for example implemented following the classic client/server principle, agent technology (Mencke and Dumke, 2007a) or Grid-based approaches (Pankratius and Vossen, 2003).

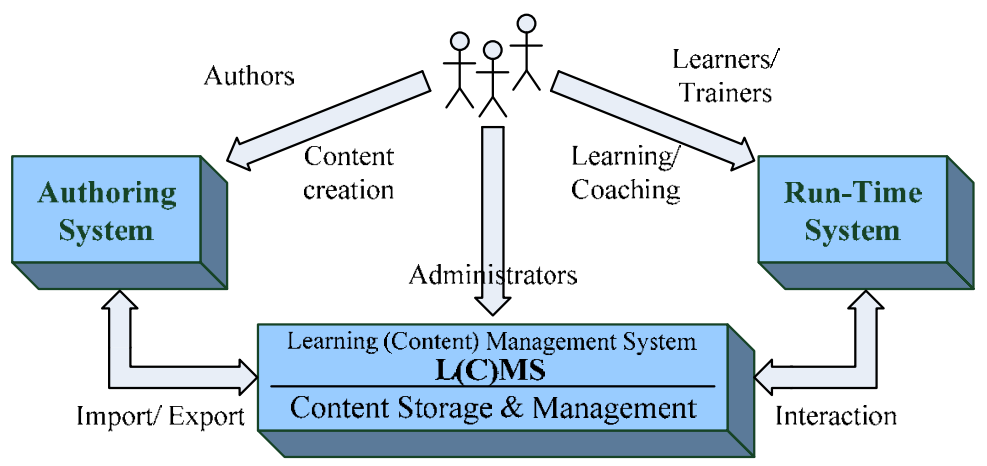

Fig. 5. General e-Learning System and Involved Roles (IMS Global Learning Consortium, Inc., 2003b)

In a typical learning environment, learners, authors, trainers and administrators are the main groups ((Pankratius et al., 2004); (Giotopoulos et al., 2005)). Sometimes these roles overlap, so trainers and authors can be the same person, especially for small e-Learning systems. The content to be presented is created by the authors using authoring systems, stored in the learning management system (LMS) and thereby made available for the learner via a run-time system. The administrator's role is about the maintenance of the e-Learning system's core. He sets up, configures, updates and maintains the L(C)MS. Especially for larger applications additional roles can be identified e.g.: content expert, instructional designer, programmer, graphic artist and project manager (Giotopoulos et al., 2005). The role of learners as content consumers is obviously clear.

\subsection{Existing Approaches for E-Learning Content Assembly Support}

Already established concepts for e-Learning content aggregation are existing standards and specification as well as educational modelling languages. They shift the focus from a content-oriented design to process orientation (Gruber, 1993). Chosen existing approaches are listed below.

○ IMS Learning Design (IMS Global Learning Consortium, Inc., 2003a)

- SCORM Content Aggregation Model (Advanced Distributed Learning (ADL), 2006)

- Educational Modelling Language (Koper, 2001)

- Learning Material Markup Language (Süss, 2000)

- PALO (Rodríguez-Artacho and Maíllo, 2004)

- Instructional Material Description Language (Gaede, 2000)

○ Essen Learning Model (Pawlowski, 2001) 
The relevance of ontologies to describe learning scenarios is motivated in (Helic, 2005), too. Here, the author proposes an ontology-based configuration mechanism with the help of didactically-sound information. Additionally, a plan is described to integrate special ontology relations for the sequencing of teaching activities:

- Local to the learning scenario

$\circ$ Relations of didactical aspects to system features

- Global to the learning scenario

- Temporal relations between activities (is-preceded-by, is-followed-by)

- Structural relations to model compositions of activities (part-of)

- Specializations of activities (kind-of)

Another difference is that the authors to provide a specialised extension of their WBTMaster system instead of targeting the provision of general expert knowledge. In (Pawlowski, 2005), the author describes the Didactical Object Model (DIN DOM) developed within the German Standardization Body. It identifies the following major components to be important for the efficient exchange and reuse of didactical expertise:

- Context: to describe the (intended) environment for the scenario

- Actors: to model individuals, groups or agents within the scenario

- Activities: to describe the didactical concepts within an activity structure

- Resource: as the materials and services that are required for the scenario Special needed sub-ontologies are already developed. As an example, there is a model of instructional objects in (Ullrich, 2004). Each concept represents a particular instructional role of a learning resource. But these roles are only implicitly modelled. Figure 6 summarizes the instructional objects defined by the author.

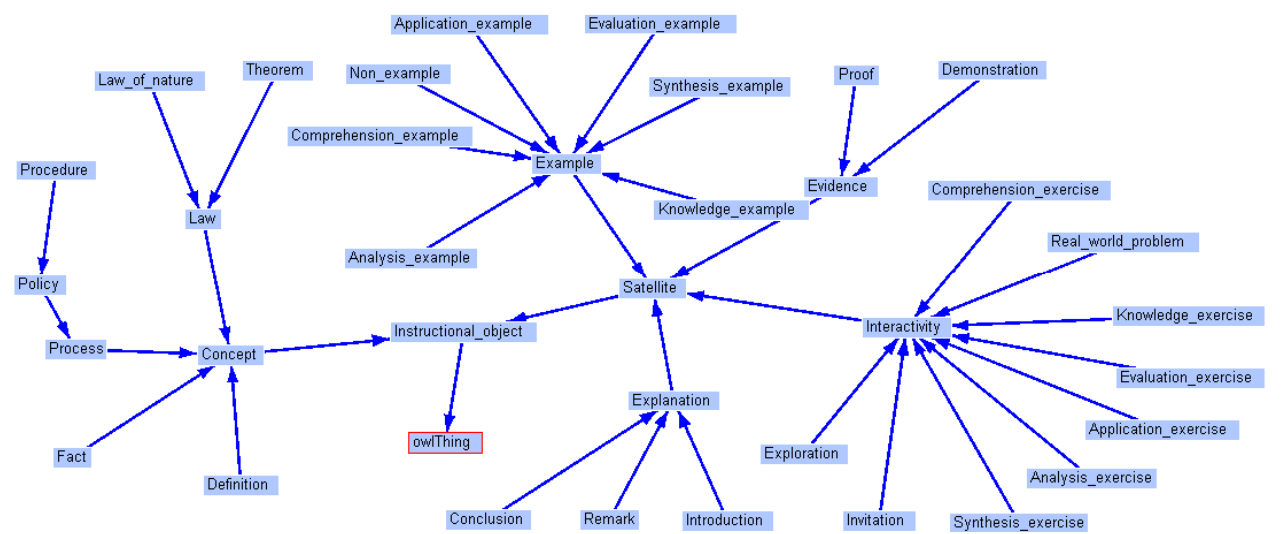

Fig. 6. Class Hierarchy of Didactical Objects (Ullrich, 2004)

Additional theoretical foundations are analyzed by ((Meder, 2001); (Meder, 2006) and (Borst, 2006)). There, additional usable taxonomies are described. They namely focus on knowledge types, presentation media, communication media, matter of fact relations, communication contribution cooperative objects as well as transactions / assignments. But for ontologybased assembly they are not yet suitable. 


\section{Ontology-Based E-learning Course Descriptions}

Following (Mencke et al., 2008d), authoring and learning are the most complex e-Learning processes. There are high degrees of freedom for the process' activities as well as for the process state's objects. The nature of the objects as well as their types may vary extremely: for example, there exist different culture-related, individual disposition-related and timely emotional influences as well as intrinsic and extrinsic motivation. Other variables are the learning situation, the individual learning type and the learning content itself.

The main goals for such e-Learning processes are specifically directed to learning next to individual knowledge increase. It is not about to classify but to individually treat learners, to keep their motivation and to provide learning possibilities that can adapt to individuals and their specific situation. The learner is a partner within the process, not a target. Some criteria for evaluation of process outcomes are:

- Content quality according to the learning goal

- Degree of the content's abstraction

- Difficulty level of content

- Flexibility of the learning system according to individual learning and life situations

○ Method conformity

- Individual learning goal adaptations by the learner

- Individual knowledge gain

- Degree of content understanding, repetition and applicability

- Achieving the didactical goal

Routine criteria and related process descriptions are not sufficient. So far, no single system provides sufficient process support that comprises all dimensions. Only an ontology-based approach can solve the occurring diversity to take account in teaching-, knowledge- and user-models ((Simon, 2002); (Mencke and Dumke, 2007b)). Semantic information is needed for the appropriate support of ad-hoc learning in its various dimensions.

As argued above, most process descriptions are not sufficient to model the complex influences that may occur within open e-Learning processes. A flexible and semantically defined approach is needed to guarantee applicability, reusability and extensibility. Ontologies as described in (Mencke and Dumke, 2007b) and (Mencke and Dumke, 2008) are suggested to fulfil these requirements. Their usage in e-Learning can be useful for numerous goals (Mencke and Dumke, 2007b) - for example they serve as:

○ Didactical ontologies for the categorization of learning goals,

- Thematic ontologies for the thematic categorization of learning material,

- Rhetoric-semantic ontologies for categorization of learning material for the creation of meaning contexts,

- Relational ontologies for the description of contextual dependencies and

- Curricular ontologies for the organizational categorization of learning material.

The ontologies' tasks, as described in this chapter, are manifold: providing a general scheme for process description, being a basis for automated content aggregation, describing didactical expert knowledge as well as serving as a starting point for process optimization. 


\subsection{A Hierarchy of Ontologies for Semantic E-Learning}

Meder (Meder, 2001) defines a didactical ontology as an approach to describe information for being able to structure cognitive learning processes. This work goes a step further and intends to use those information also for the ontology-based modelling of didactical expertise - didactical ontologies. In the following, approaches for an ontology-based provision of didactical expertise as well as for course structure specification are introduced.

For the hierarchy of ontologies, a 5-level structure is proposed to reach the intended advantages.

\section{Level 0: Ontology Meta Structure}

Level 0 contains the most general ontology of the proposed set. It depicts a general description of a didactic strategy. Its purpose is to define the scheme for an ontology-based realization of the order of learning content to achieve an optimal learning result as well as the description of didactical expertise. Human experiences with the learning and teaching processes can be integrated in those ontologies. These implicit quality aspects result in a substantial quality gain. Timed strategic elements need to be adaptively chosen to fit certain context, learner or teacher-defined requirements:

Figure 7 presents the developed top-level ontology. The central concepts are the LearningStep and Condition class. A LearningStep is the reference to a part of a didactical approach. Further refinement is supported by the possibility to divide a learning step into several sub learning steps. Therefore, the relation leadsToSubLearningStep is created to point to the first LearningStep node that will compound the sub learning steps. The property isFirstLearningStep must be set true to mark this first node. According to this, the property isLastLearningStep must be set true for the last node. To permit a return to the main didactical flow, the sub nodes reference to their root node through the relation hasAsRootLearningStep. Additional relationships point to describing (sometimes taxonomic) ontologies:

○ hasActivityType points to certain activities which the current learning step should cover.

- hasLearningObjective points to an ontology describing learning objectives

- hasIntendedStudentRole points to a description, where possible student roles a listed

- hasIntendedResource points (technical) resources that are intended to be used

- hasIntendedTechnique points special techniques/approaches for teaching

- hasAssessment points to suggestions for certain assessment types

- hasIntendedCardinality describes the type of interaction according to the number of participants 


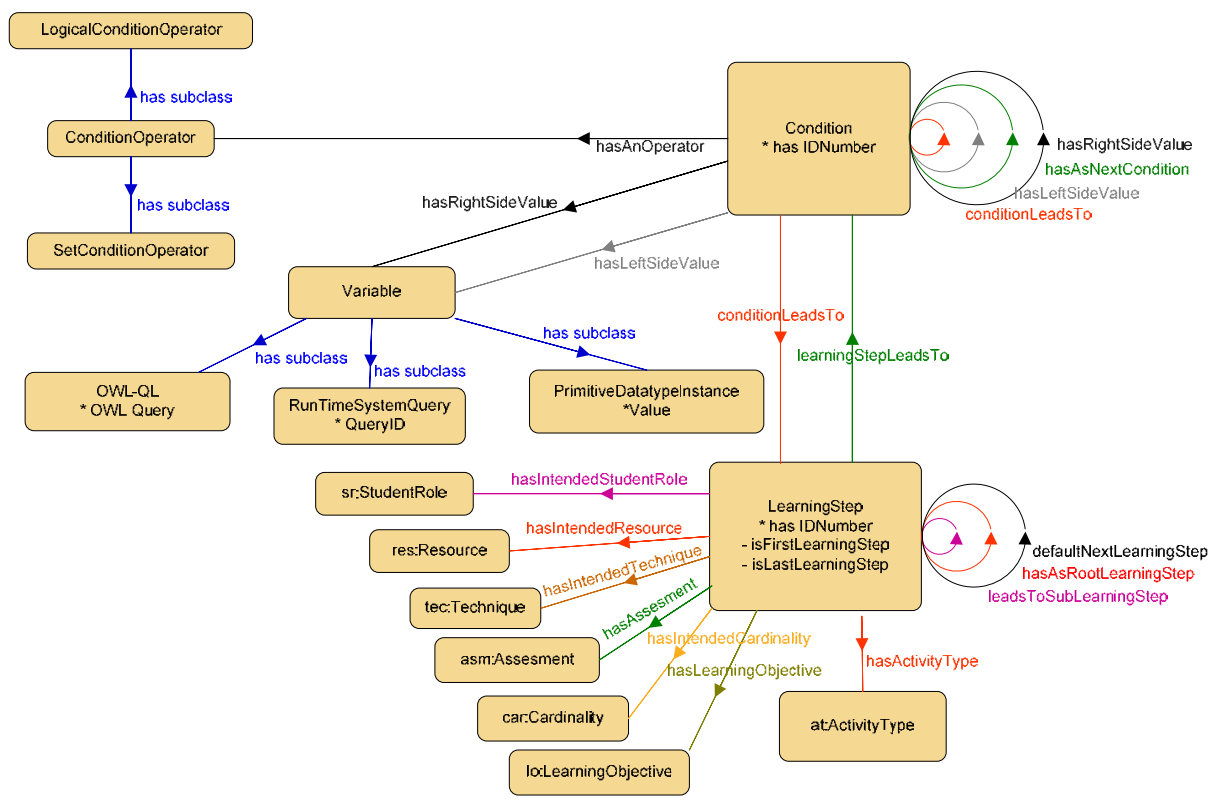

Fig. 7. Level 0 Didactical Ontology (Mencke and Dumke, 2007b)

The condition concept is used to model restrictions to a path, permitting the runtime environment of an e-Learning system to decide the next appropriate path through the learning content for the current user in his specific context. Both main concepts are used to model a didactic in this way:

1. Identify the first LearningStep

2. Follow the learning path for the first condition that delivers a true result Therefore, a LearningStep points to a Condition with a learningStepLeadsTo relationship. A Condition itself redirects the learning path to one other LearningStep with the conditionLeadsTo relationship, if its result is true. Multiple learning paths can be modelled by integrating multiple Condition individuals.

To support those alternative ways through the e-Learning course, additional aspects are integrated into the ontology. A first one is a hierarchy of conditions. If one fails, the conditionLeadsTo relationship points to the next condition to be checked. Another one is the possibility to depict sequences of conditions by using the hasAsNextCondition relationship; the last condition of a sequence must point to a LearningStep. The default relationship defaultNextLearningStep between two learning steps provides an alternative for the case where no condition is fulfilled and must appear only once. Figure 8 exemplary visualizes some aspects described above. 


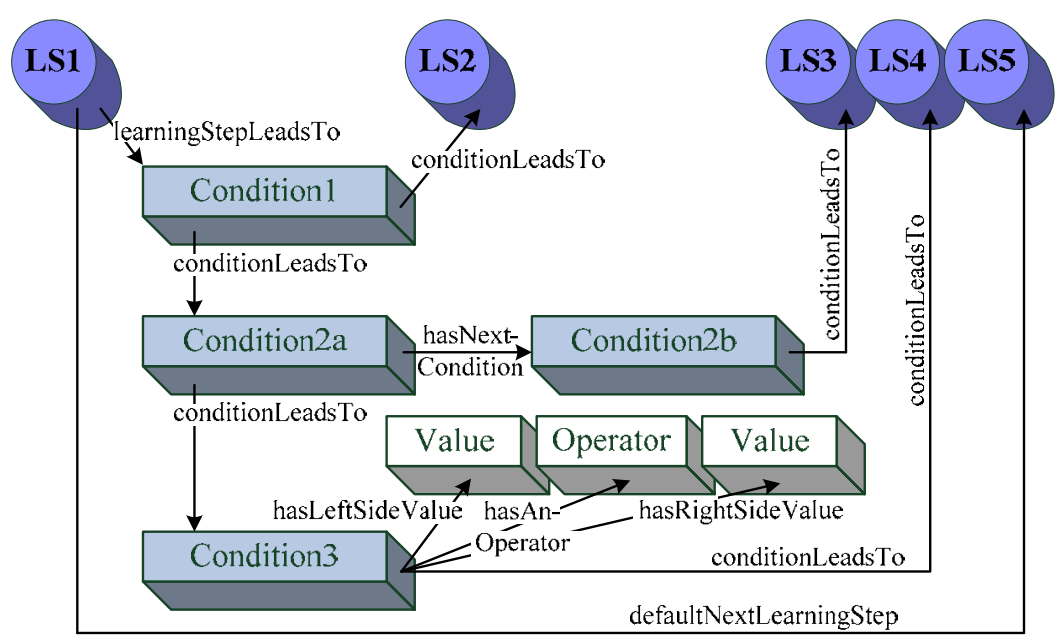

Fig. 8. Hierarchical Conditions for Multiple Learning Paths (Mencke and Dumke, 2007b)

The conditions themselves are described by three (two, if a unary operator is used) additional relationships. The relationships hasLeftSideValue and hasRightSideValue point either to another condition or to a Variable that can be of type PrimitiveDatatypeInstance, $O W L-Q L$ or RuntimeSystemQuery. The first type has the anyType-property value and is used to model variables like the " 5 " within the following conditional expressions: "If (NumberOfTries) is GreaterThan 5". The NumberOfTries-variable is of type OWL-QL and the query is stored as a string within the OWLQuery property. The RuntimeSystemQuery has a string-property, too. QueryID will be used by an e-Learning runtime system to locate an internal condition. That is internally analyzed and delivers back a Boolean value for the comparison. The ontology-intern condition must look like: "If (runtimeCondition1) isEqual true". The relationship hasAnOperator points to a ConditionOperator that defines the set and logical operators. For conditions as well as for learning steps, the mandatory property hasIDNumber was created. These IDs are used to provide the runtime environment a way to identify the path that the user has gone through.

\section{Level 1: Basic Didactical Ontology}

This level may reveal an inner hierarchical structure, too. It is directed toward to description of general didactical strategies, based on the level 0 ontology. The problem-based learning (PBL) approach was chosen for further implementation. PBL is a didactic that begins with a presented problem and is followed by a student-centred inquiry process (Trevena, 2007). Fundamental principles base on the work of Barrows and Schmidt ((Barrows, 1986) and (Schmidt, 1983)).

Figure 9 visualizes the ontology focusing on Schmidt's seven steps in problem-based learning. This implemented PBL ontology describes the seven basic steps that a PBL didactical approach should have according to (Trevena, 2007), namely: clarify terms and concepts, define the problem, analyze the problem, draw systematic inventory, formulate learning objectives, collect additional information and synthesize and test the new 
information. These steps are defined as individuals of a LearningStep and, as there is no special condition to the transition between them, only the defaultNextLearningStep relationship is used. The activity types for each LearningStep are chosen based on what should be performed by the learner.

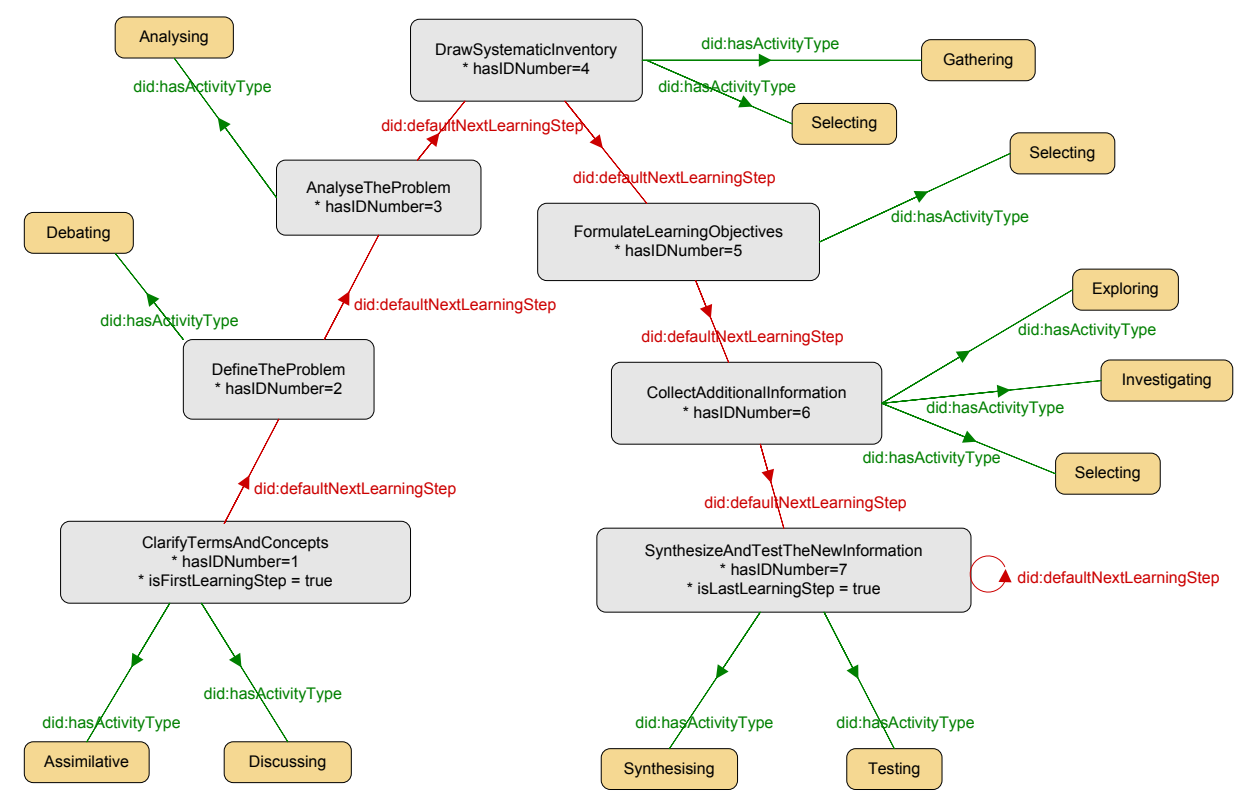

Fig. 9. Problem-Based Learning Didactic Level 1 Ontology (Mencke and Dumke, 2007b)

\section{Level 2: Refined Didactical Ontology}

Such ontologies contain the leaf nodes of the hierarchy, each describing an applicable didactical approach. Here, for example the micro didactics of Meder (Meder, 2006) or the didactical models of (Flechsig, 1996) are integrated. Figure 10 defines an ontology for another special problem-based learning didactic. It is adopted from (Mertens, 2002) and bases on (Hahn, 1971).

The presented didactical approach consists of six main steps, namely problem definition phase, research phase, evaluation phase, decision phase, implementation phase and control phase. These main learning steps are further refined into sub learning steps and related to appropriate activity types. 


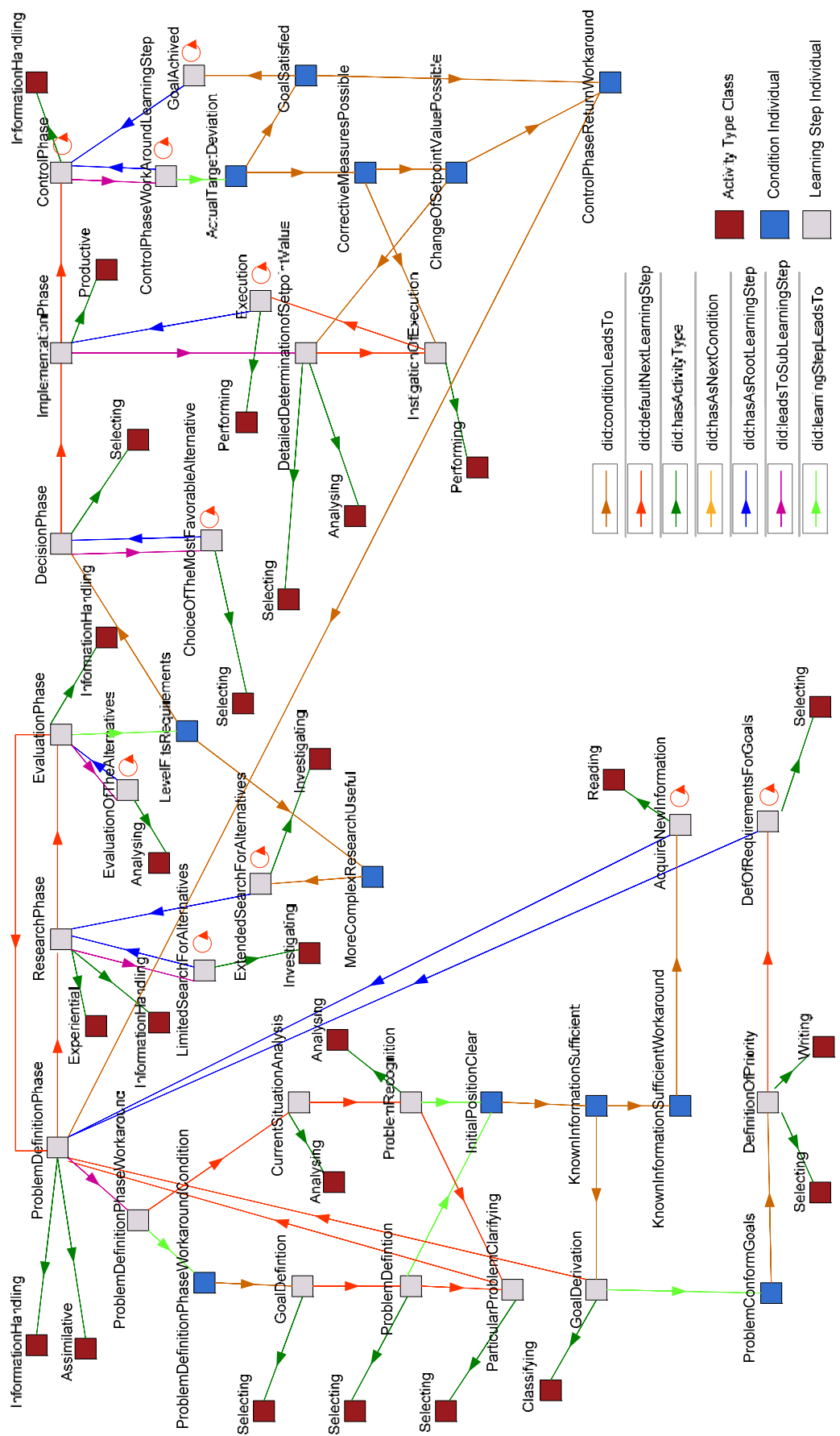

Fig. 10. Problem-Based Learning Didactic Level 2 Ontology (Mencke and Dumke, 2007b) 


\section{Level 3: Recombination of Didactical Ontologies}

This level is directed to the approach of individual (recombined) adapted didactics. The idea behind is, that individual approaches of specific teachers, tutors or scientists should be made available and usable, too. The trivial usage is to identify sub elements of the course that are didactically decoupled or only loosely coupled. These (Sub-) LearningSteps are affiliated with each other with the standard defaultNextLearningStep relationship or reusable relationships that for example point forward, if the current LearningStep was successfully completed. The more complex problem is the identification of inter-didactic relationships within certain contexts and their ontology-based modelling.

\section{Level 4: Extension of Didactical Ontologies to Course Ontologies}

To be able to depict the specific structure of an e-Learning course, the level 0 ontology is extended by an additional concept and certain properties (see Figure 11). The LearningObject is integrated from a developed LOM-Ontology comprising metadata instances of existing Learning Objects. Next to the hasIDNumber variable, storing an ID of the currently described Learning Object, this concept has two datatype properties - namely isFirstLearningObject and isLastLearningObject. In addition to them object properties are integrated to point from a LearningStep to a LearningObject as well as from a LearningObject to another LearningObject. By this procedure, it is possible to refine a LearningStep as a sequence of LearningObjects.

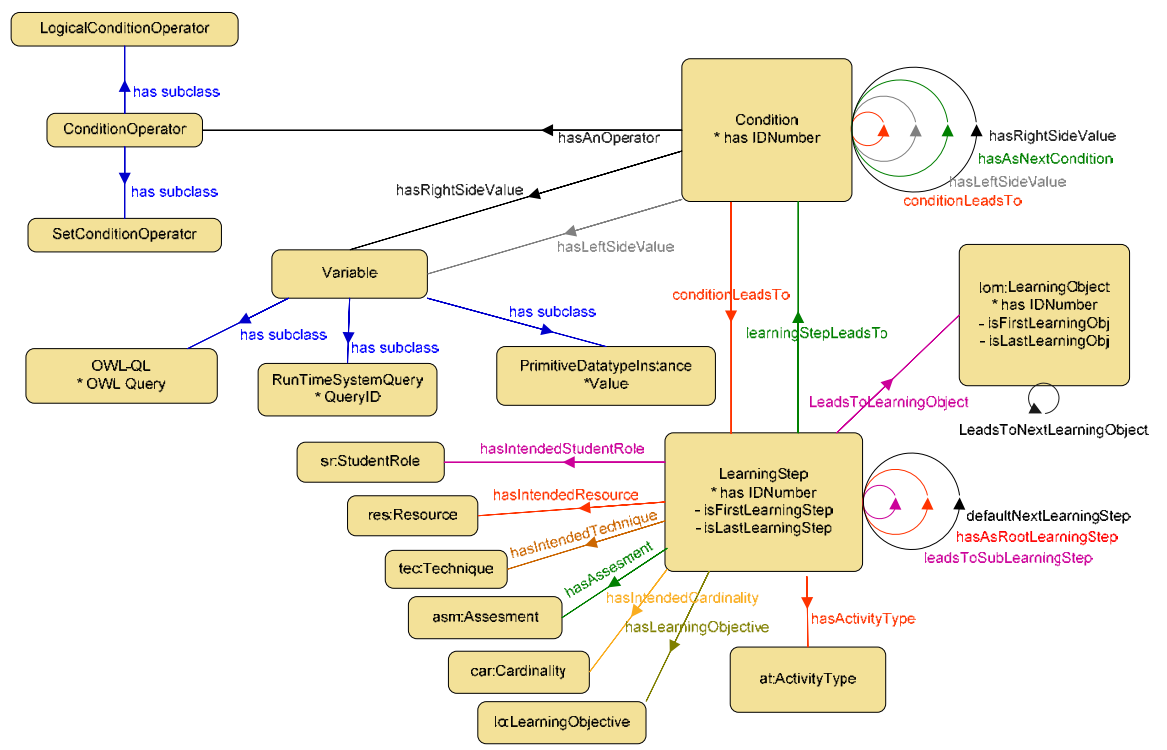

Fig. 11. Level 4 Didactical Ontology (extended from (Mencke and Dumke, 2007b))

Summarized, based on this information ontology-based descriptions for didactical expertise as well as e-Learning course structures is introduced. Ontologies are used to model didactical teaching approaches developed by pedagogical experts. Thereby, they provide a useful tool for their semi-automatic integration into e-Learning authoring processes. Hierarchical refinement as well as individual recombination is supported. These structures 
are the starting point for e-Learning course descriptions based on Learning Objects. A prototypical tool is shown in Figure 12. Based on didactical ontologies the creation of courses is possible. Thereby, didactical expertise, generative course structures as well as Learning Objects enriched with domain information are the basis for the course author to create e-Learning courses.

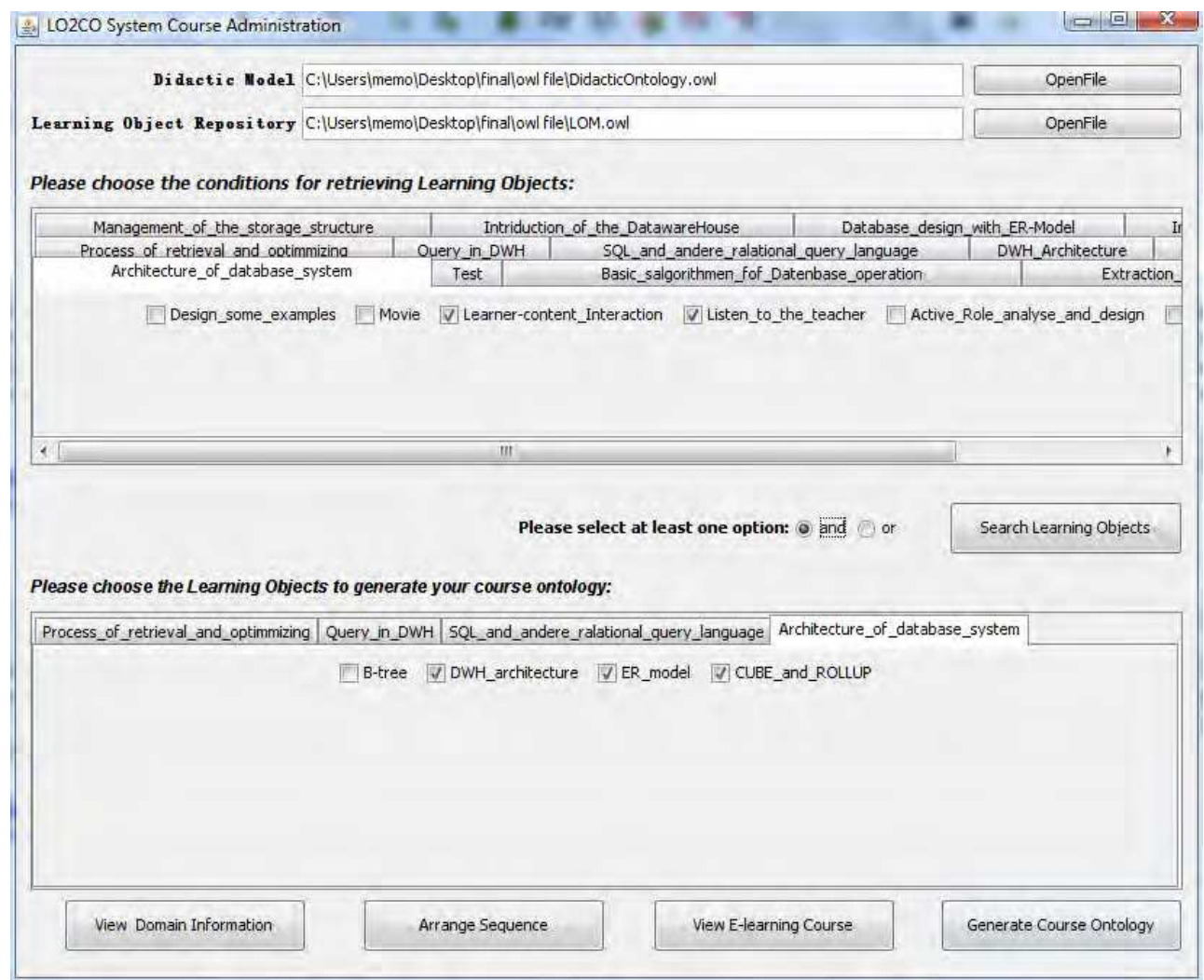

Fig. 12. Screenshot of a Tool for Ontology-Based E-Learning Course Generation (Zhang, 2009)

\section{Semantics-Supported Enrichment of Assembled E-Learning Content}

Having created such ontology-based e-Learning courses is only the first step. Individual learning is more flexible. The learner's awakened interest or respectively his identified knowledge gap should be satisfied by additional, semantically-related e-Learning content. Therefore, this next part will be dedicated to new approaches for proactive, semanticsdriven content enrichment. 


\subsection{Enrichment Algorithm}

E-Learning-related content is any portion of data that can be displayed to a user by the runtime part of an e-Learning system. According to this, content enrichment describes the process of searching and displaying additional information, being semantically related to the information of the e-Learning content.

For the identification of starting points for enrichment in an educational content an 'Enrichment Algorithm' is developed in (Mencke et al., 2008b). The enrichment component proactively scans the requested e-Learning resources, integrates new semantically related information and thereby adapts the presented information.

In the first step, an identification of appropriate ontological elements within the ontology $O(C, P)$ with its concepts $C$ and properties $P$ is performed. The function $f^{\text {naming }}(a)$ (Formula 1) delivers a human readable name of an ontological element $a$. The tuples, containing ontology elements $a_{i}$ and their names determined using $f^{\text {naming }}\left(a_{i}\right)$ constitute the set $T^{O}$ as shown in Equation 2.

$$
\begin{gathered}
f^{\text {naming }}: \text { OntolElement } \mapsto \text { String } \\
T^{O}=\left\{\left\langle a_{i}, f^{\text {naming }}\left(a_{i}\right)\right\rangle \mid a_{i} \in\left(C \cup\left(P \backslash P_{\text {tax }}\right)\right)\right\}
\end{gathered}
$$

At this point, taxonomic relations within the ontology $\left(P_{t a x}\right)$ are neglected, because $f^{\text {naming }}(a)$ cannot deliver any useful results for them.

A second step is the inflation of $T^{O}$ with appropriate additional terms, for example taken from the WordNet specifications for the English language (Princeton University, 2006). The function $f^{s y n}(a)$ delivers additional terms (synonyms) (Formula 3). The tuples of the extended set $T^{O+S Y N}$ connect ontology elements $a_{i}$ with their synonyms (Equation 4).

$$
\begin{gathered}
f^{\text {syn }}: \text { String } \mapsto\{\text { String }, \ldots\} \\
T^{O+S Y N}=T^{O} \cup\left\{\left\langle a_{i}, b_{i}\right\rangle \mid a_{i} \in\left(C \cup\left(P \backslash P_{\text {tax }}\right)\right), b_{i} \in f^{\text {syn }}\left(f^{\text {naming }}\left(a_{i}\right)\right)\right\}
\end{gathered}
$$

The function $f^{\text {concept }}(x)$ (Formula 5) applies to both, metadata $L O^{M}$ and the content $L O^{C}$ of learning objects $L O$ (Formula 6) and extracts names of concepts contained in them. A particular implementation of $f^{\text {concept }}$ can use classic mining algorithms. For each learning object $L O_{i}$, the initial set $T_{i}^{L+S Y N}$ of concept names and their synonyms, that can serve as starting points of the enrichment, can be determined as shown in the Equation 8.

$$
\begin{gathered}
f^{\text {concept }}: \text { DataObject } \mapsto\{\text { String,... }\} \\
L O=\left\{L O_{i}\right\}=\left\{\left\langle L O_{i}^{M}, L O_{i}^{C}\right\rangle\right\} \\
C N_{i}=f^{\text {concept }}\left(L O_{i}^{M}\right) \cup f_{i}^{\text {concept }}\left(L O_{i}^{C}\right) \\
T_{i}^{L+S Y N}=C N_{i} \cup \bigcup_{x \in C N_{i}} f^{s y n}(x)
\end{gathered}
$$


The next step is to match the identified concepts of the learning objects with the human readable names of ontological elements (Equation 9). $T_{i}^{S}$ maps ontological elements to possible enrichment points within the learning objects.

$$
T_{i}^{S}=\left\{\langle c, d\rangle \mid d \in T_{i}^{L+S Y N},\langle c, d\rangle \in T^{O+S Y N}\right\}
$$

$T_{i}^{S}$ is a set of tuples $\langle c, d\rangle$ where $d$ is a concept of the educational content and $c$ is the associated ontological element. The set of all $d$ is $D$ (Equation 10).

$$
D=\left\{d \mid\langle c, d\rangle \in T_{i}^{S}\right\}
$$

The algorithm's next part is the selection of identified enrichment points $D^{\prime} \subseteq D$ within the Learning Object. Possible implementations can limit the set of enrichment points, for example by the selection of the first appearance of the enrichment points. The semantic relevance is proposed as the key factor. For its determination several approaches can be (combined) implemented: (a) choose those enrichment points that are most relevant based on certain mining algorithms, (b) choose those enrichments points that are most relevant based on the semantic relevance according to the metadata of the LO, (c) choose those enrichment points that are most relevant based on the ontological relevance of the associated ontological elements. For the last option, certain ontology metrics can be useful (Mencke et al., 2008a).

On the basis of the set $R O$ (Equation 12) containing all ontological elements related to the selected enrichment points, and the Semantic Window approaches described in (Mencke, 2008), an additional set of ontological elements can be computed. It will be referred to as $W$.

$$
\begin{gathered}
f^{\text {onto }}: \text { String } \mapsto\{\text { OntolElement }, \ldots\} \\
R O=\bigcup_{d \in D^{\prime}} f^{\text {onto }}(d)
\end{gathered}
$$

The next step determines the amount of additional information $E C$ that is used to enrich the educational content (Formula 13 and Equation 14).

$$
\begin{gathered}
f^{\text {enrich }}: \text { OntolElement } \\
E C=\{\text { EnrichmentContent }, . . .\} \\
\bigcup_{r \in R O \bigcup W} f^{\text {enrich }}(r)
\end{gathered}
$$

The presentation is not part of the algorithm above, but results in the highlighting of all selected $d \in D^{\prime}$ and the selective displaying the prepared enrichment content $E C \subseteq E C^{\prime}$ as described in the next section.

\subsection{Cost-Based Semantic Windows}

The cost-based Semantic Window approach is one suitable option for the determination of semantically related content elements. Additionally to the distance-based approach it is 
described in detail in (Mencke, 2008). In the following, a short overview about the costbased idea is presented.

For the enrichment the concept of a 'Semantic Window' is defined. This term describes a set of elements of a given ontology within a certain multi-dimensional distance. Dimensions for its definition are related to the concepts of an ontology as well as to the datatype properties. Furthermore, instances and taxonomic as well as non-taxonomic relations are taken into consideration (Mencke et al., 2008b).

The function $f^{\cos t}$ returns the "cost" of the transition between two nodes, given their types as well as the sequence of already accepted nodes (Formula 15). For the combinations of ontological elements' types, between which no transition is possible, the cost function is assumed to return the positive infinity.

$$
f^{\cos t}: \text { Type, Type, }\langle\text { Node, }, . .\rangle \mapsto \text { Integer }
$$

Function $f^{\text {type }}$ returns the type of a given ontological element (a member of the enumeration 17). New types of ontological elements can be introduced by splitting the sets of ontological elements of a particular type on the basis of some constraints (subclassing). The domain of $f^{\text {cost }}$ for these new types obviously cannot be broader as for the original type.

$$
f^{\text {type }}: \text { OntolElement } \mapsto \text { Type }
$$

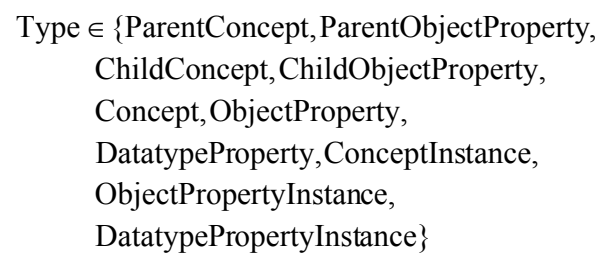

Elements of a tuple $\left\langle n_{0}, \ldots, n_{m}\right\rangle, n_{i} \in O, m \in \mathbb{N}$ are included to the Semantic Window, if $n_{0}$ is the enrichment point of the enrichment and inequality 18 resolves to true, where $A$ is the cost restrictor ("the size of the Semantic Window").

$$
\sum_{i=0}^{m-1} f^{c o s t}\left(f^{t y p e}\left(n_{i}\right), f^{\text {type }}\left(n_{i+1}\right),\left\langle n_{0}, \ldots, n_{i}\right\rangle\right) \leq A
$$

In Figure 13, an example for the Semantic Window is given. Concept $\mathrm{C}_{6}$ is the enrichment point around which the Semantic Window is created. For the sake of simplicity, datatype properties are not taken into consideration. The cost function $f^{\text {cost }}$ is given in Table 1 and the maximum cost is $\mathrm{A}=3$. Filled circles represent concepts, filled squares represent instances and filled diamonds on arrows represent object properties, all being located within the range of the Semantic Window around $\mathrm{C}_{6}$. 


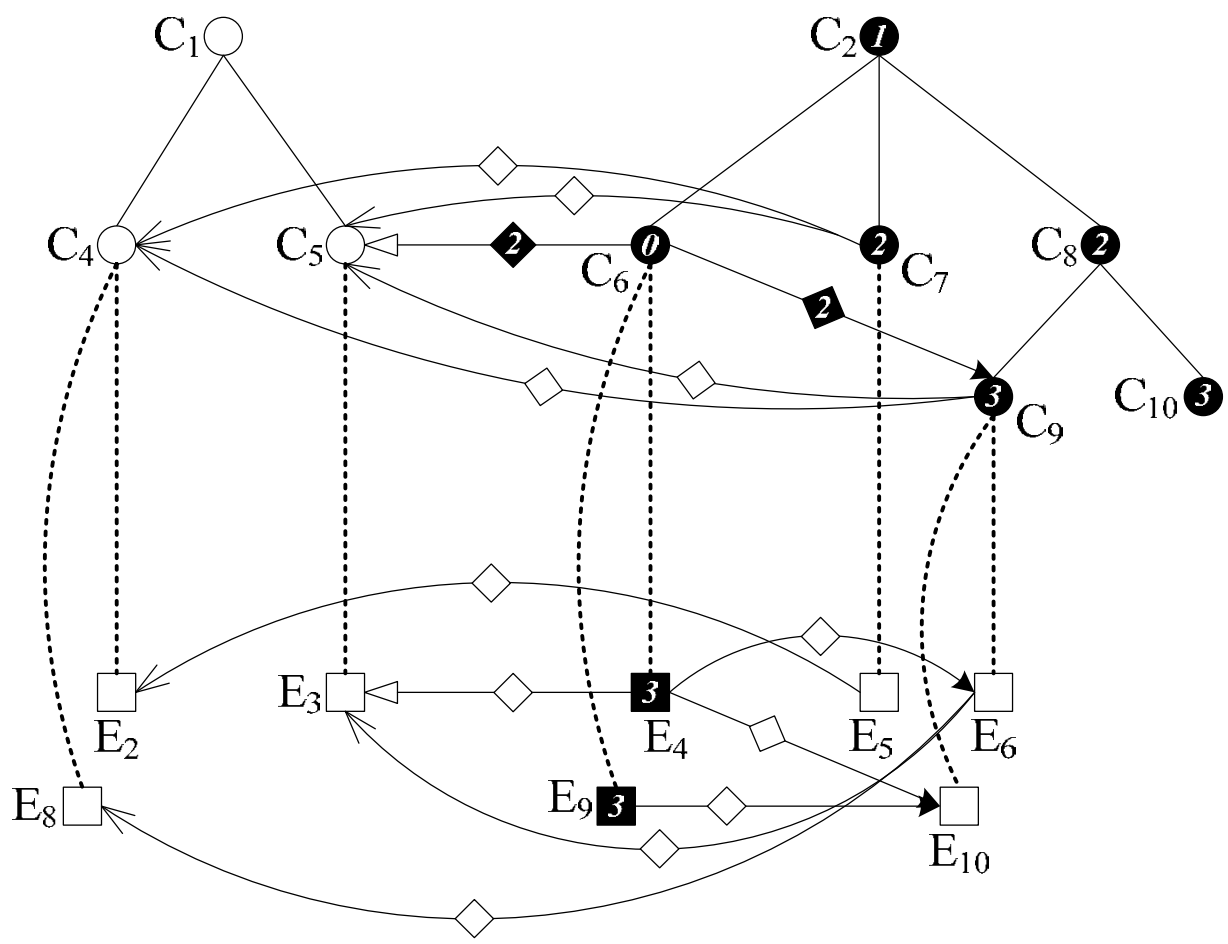

Fig. 13. Example of a Semantic Window with Enrichment Point $C_{6}$, Cost Restrictor $A=3$ and the Transition Costs Given in Table 1

\begin{tabular}{|c|c|c|c|c|c|c|c|c|}
\hline & 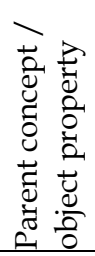 & 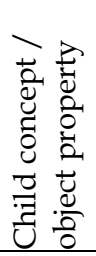 & $\begin{array}{l}\overrightarrow{0} \\
0 \\
0 \\
0 \\
0\end{array}$ & 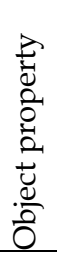 & 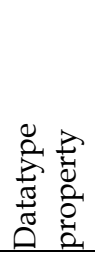 & 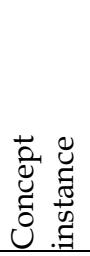 & 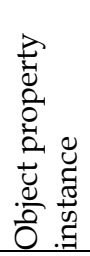 & 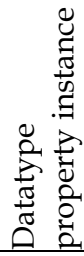 \\
\hline Concept & 1 & 1 & $\infty$ & 2 & 2 & 3 & $\infty$ & $\infty$ \\
\hline Object Property & 1 & 1 & 2 & $\infty$ & $\infty$ & $\infty$ & 3 & $\infty$ \\
\hline Datatype property & $\infty$ & $\infty$ & 2 & $\infty$ & $\infty$ & $\infty$ & $\infty$ & 3 \\
\hline Concept instance & $\infty$ & $\infty$ & 3 & $\infty$ & $\infty$ & $\infty$ & 2 & 2 \\
\hline Object property instance & $\infty$ & $\infty$ & $\infty$ & 3 & $\infty$ & 2 & $\infty$ & $\infty$ \\
\hline $\begin{array}{r}\text { Datatype property } \\
\text { instance }\end{array}$ & $\infty$ & $\infty$ & $\infty$ & $\infty$ & 3 & 2 & $\infty$ & $\infty$ \\
\hline
\end{tabular}

Table 1. Example of Transition Costs Between Ontological Elements (Mencke et al., 2008b). 


\subsection{Prototypical Tool for Ontology-Based Content Enrichment}

The prototype focuses on the semantic-based selection of entities. One advantage of the Semantic Window approach in this context is the well-defined definition of a semantic range around an entity. By this, not only the selection of semantically-fitting entities is realised. It also becomes possible to identify additional content based on the semantic and the knowledge structure of the targeted domain.

Figure 14 presents a screenshot of a tool that uses distance-based Semantic Windows for Web content enrichment (see Figure 15). Users can add new enrichment content in order to complete the available data sources and thereby collaborate on quality improvement.

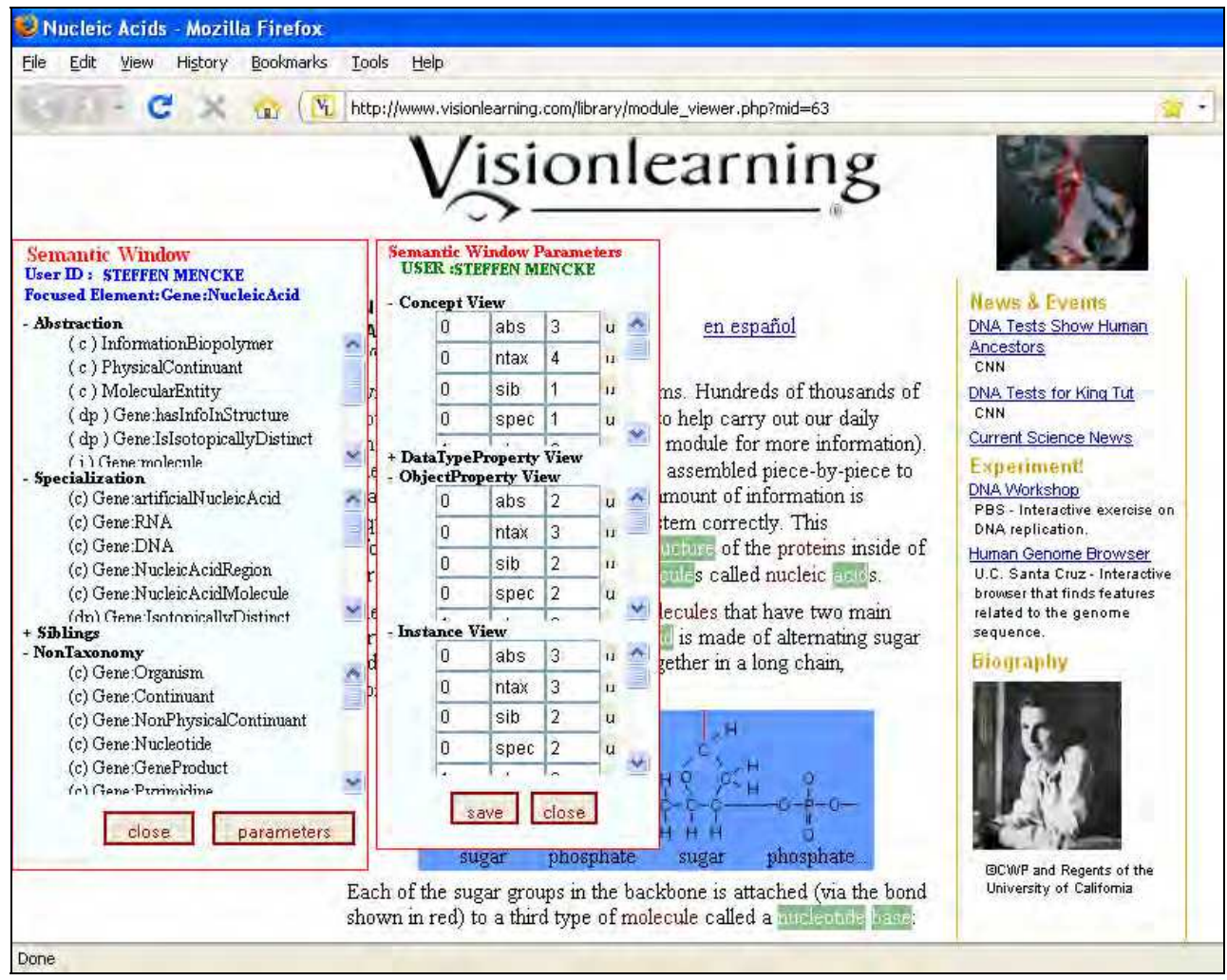

Fig. 14. Distance-Based Semantic Windows for Content Enrichment 


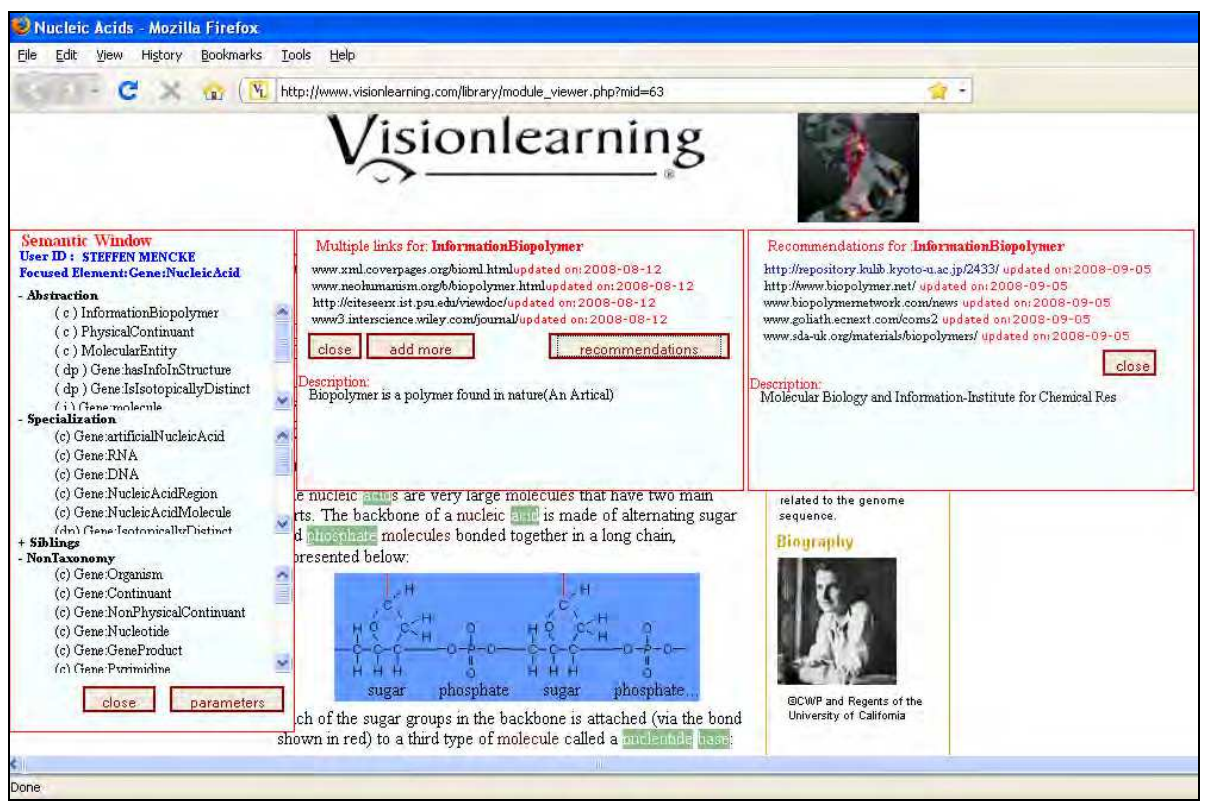

Fig. 15. Enriched Web Page Based on Distance-Based Semantic Windows

\section{Conclusion}

The provision of content, especially information, is one of the most important lifelines in the current information society. It is a fundamental process of the current information society multimedial knowledge is presented on Web pages, virtual objects are visualized in Virtual Reality applications, Web services are used in business processes and e-Learning content can be learned in educational systems. Especially the provision of information content is targeted in this work. It is the step of the information life cycle where its value is at highest (Tallon and Scannell, 2007). It is necessary to pre-select, prepare and provide them in adequate ways to the user.

Especially for e-Learning this is a tremendous venture. It was the aim of this chapter to propose semantic technology approaches in order to enable the usage of didactical expertise as well as adapted content provision. Semantic Web technologies, especially ontologies, are seen as the key approach with tremendous potential to future applications (Hendler, 2008). They "fit so well with education, by building a strong platform for it, by bringing reflection and by interweaving everything." (Devedžić, 2006).

In this chapter and the referenced literature, numerous approaches are described that fundamentally base on Semantic Web technologies in order to enhance selected aspects of eLearning. Ontologies were for example used for the description of didactical expertise, course definitions, learning content recommendations, course enrichment, quality driven content selection - to name only a few. 


\section{References}

Advanced Distributed Learning (ADL) (2006a). Sharable Content Object Reference Model (SCORM) 2004 3rd Edition Content Aggregation Model

American Society for Training \& Development (ASTD) (2008). American Society for Training \& Development (ASTD) (2008). E-learning Glossary. URL: http://www. learningcircuits.org/glossary.html

Anghel, C. \& Salomie, I. (2003). JADE based solutions for knowledge assessment in eLearning environments. EXP - in search of innovation (Special Issue on JADE)

Antoniou, G. \& van Harmelen, F. (2004). A Semantic Web Primer. MIT Press

Barrows, H. (1986). A taxonomy of problem-based learning methods. Medical Education, Vol. 20, No. 6, pp. 481-486

Berners-Lee, T., Hendler, J., \& Lassila, O. (2001). The Semantic Web. Scientific American, Vol. 284, No. 5, pp. 34-44

Boley, H., Tabet, S., \& Wagner, G. (2001). Design Rationale of RuleML: A Markup Language for Semantic Web Rules. Proceedings of the first Semantic Web Working Symposium (SWWS 2001), pp. 381-401, Stanford, USA

Borst, T. (2006). Ontologies for Semantic Annotation of Digital Learning Material (in German). Technical report, Fernuniversität Hagen

Chandrasekaran, B., Josephson, J. R., \& Benjamins, V. R. (1999). What Are Ontologies, and Why Do We Need Them? IEEE Intelligent Systems, Vol. 14, No. 1, pp. 20-26

Cost, R. S., Finin, T. W., Joshi, A., Peng, Y., Nicholas, C. K., Soboroff, I., Chen, H., Kagal, L., Perich, F., Zou, Y., \& Tolia, S. (2002). ITtalks: A Case Study in the Semantic Web and DAML+OIL. IEEE Intelligent Systems, Vol. 17, No. 1, pp. 40-47

Daconta, M. C., Smith, K. T., \& Obrst, L. J. (2003). The Semantic Web: A Guide to the Future of $X M L$, Web Services, and Knowledge Management. John Wiley \& Sons, Inc.

Devedzic, V. (2006). Semantic Web and education. Springer's Integrated Series in Information Systems. New York: Springer

Encyclopædia Britannica - Online (2008). Semantics. Link: http://www.britannica.com/ eb/article-9110293/semantics

Fensel, D., van Harmelen, F., Horrocks, I., McGuinness, D. L., \& Patel- Schneider, P. F. (2001). OIL: An Ontology Infrastructure for the Semantic Web. IEEE Intelligent Systems, Vol. 16, No. 2, pp. 38-45

Fikes, R. (1998). Multi-Use Ontologies. Link: http://wwwksl.stanford.edu/ people/fikes/cs222/1998/Ontologies/sld001.htm. Stanford University

Flechsig, K.-H. (1996). Little Handbook of Didactical Models (in German). Neuland

Gaede, B. (2000). The Instructional Material Description Language and the production system for interactive learning software ProfiL (in German). Proceedings of the 10. Arbeitstreffen der GI-Fachgruppe Intelligente Lehr-/ Lernsysteme, Hamburg, Germany

Giotopoulos, K. C., Alexakos, C. E., Beligiannis, G. N., \& Likothanassis, S. D. (2005). Integrating agents and computational intelligence techniques in e-learning environments. Proceedings of International Enformatika Conference, pp. 231-238

Gómez-Pérez, A. \& Corcho, O. (2002). Ontology Specification Languages for the Semantic Web. IEEE Intellgient Systems, Vol. 17, No. 2, pp. 54-60

Gruber, T. R. (1993). A Translation Approach to Portable Ontology Specifications. Knowledge Acquisition, Vol. 5, No. 2 pp. 199-220 
Hahn, D. (1971). Decision process and case method (in German). Decision Cases in Business Practice (in German), Wiesbaden: Gabler Publ.

Heflin, J. \& Hendler, J. (2001). A Portrait of the Semantic Web in Action. IEEE Intelligent Systems, Vol. 16, No. 2, pp. 54-59

Helic, D. (2005). An Ontology-Based Approach to Supporting Didactics in Elearning Systems. Proceedings of the 5th IEEE International Conference on Advanced Learning Technologies, pp. 174-176, Kaohsiung, Taiwan

Hendler, J. (2001). Agents and the Semantic Web. IEEE Intelligent Systems, Vol. 16, No. 2, pp. 30-37

Hendler, J. (2008). Web 3.0: Chicken Farms on the Semantic Web. IEEE Computer, Vol. 41, No. 1, pp. 106-108

Hendler, J. \& McGuinness, D. L. (2000). The DARPA Agent Markup Language. IEEE Intelligent Systems, Vol. 16, No. 6, pp. 67-73

IMS Global Learning Consortium, Inc. (2003a). IMS Learning Design Specification. Link: http://www.imsglobal.org/learningdesign/index.html.

IMS Global Learning Consortium, Inc. (2003b). IMS Content Packaging Best Practice Guide

Juneidi, S. J. \& Vouros, G. A. (2005). Engineering an e-learning application using the ARL Theory for agent oriented software engineering. Proceedings of 2005 AAAI Fall Symposium, Arlington, Virginia, USA. MIT press.

Koper, R. (2001). Modeling Units of Study from a Pedagogical Perspective the Pedagogical MetaModel behind EML. URL: http://dspace.ou.nl/bitstream/1820/36/1/ Pedagogical +metamodel+behind+EMLv2.pdf.

Meder, N. (2001). Didactical Ontologies (in German). URL: http://cweb.uni-bielefeld. de/agbi/cgi-bin-noauth/cache/VAL_BLOB/167/167/63/did.pdf

Meder, N. (2006). Web-Didactic. Bielefeld: Bertelsmann Publ.

Mencke, N., Mencke, S., \& Höpfner, A. (2008a). An Online Virtual Vocational Training System. Proceedings of the 2008 International Technology, Education and Development Conference (INTED 2008), Valencia, Spain

Mencke, S. (2008). Proactive Ontology-Based Content Provision in the Context of e-Learning, PhD Thesis, Otto-von-Guericke University Magdeburg, Germany

Mencke, S., Kunz, M., \& Dumke, R. (2008b). Steps to an Empirical Analysis of the Proactive Class Schedule. IEEE Multidisciplinary Engineering Education Magazine, Vol. 3, No. 3, pp. 100-103

Mencke, S., Zbrog, F., \& Dumke, R. (2008d). Useful e-Learning Process Descriptions. Proceedings of the 4th International Conference on Web Information Systems and Technologies (WEBIST 2008), pp. 460-463, Funchal, Portugal. INSTICC Press

Mencke, S. \& Dumke, R. (2007a). Agent-Supported e-Learning. Technical Report 07-08, Ottovon-Guericke University of Magdeburg

Mencke, S. \& Dumke, R. (2007b). A Hierarchy of Ontologies for Didactics-Enhanced Elearning. In Auer, M. E., editor, Proceedings of the International Conference on Interactive Computer-aided Learning (ICL2007), Villach, Austria

Mencke, S. \& Dumke, R. (2008). Didactical Ontologies. Emerging Technologies in e-Learning, Vol. 3, No. 1, pp. 65-73

Mertens, H. (2002). Conception and Development of a Problem-oriented Interaction Component for the Depiction of Economic Case Studies in Hypermedia Teaching/Learning Systems (in German). PhD thesis, University of Würzburg, Germany 
Narayanan, S. \& McIlrath, S. (2001). Semantic Web Services. IEEE Intelligent Systems, Vol. 16, No. 2, pp. 46-53

Pankratius, V., Sandel, O., \& Stucky, W. (2004). Retrieving Content with Agents in Web Service E-Learning Systems. Proceedings of the Symposium on Professional Practice in AI, IFIP WG12.5 - First IFIP Conference on Artificial Intelligence Applications and Innovations (AIAI), Toulouse, France

Pankratius, V. and Vossen, G. (2003). Towards E-Learning Grids: Using Grid Computing in Electronic Learning. Proceedings of the IEEE Workshop on Knowledge Grid and Grid Intelligence, pp. 4-15, Halifax, Canada

Pawlowski, J. M. (2001). The Essen Learning Model: A Model for the Development of ComputerSupported Learning Environments. PhD thesis, University of Essen

Pawlowski, J. M. (2005). The Didactical Object Model: Managing Didactical Expertise. Proceedings of the 5th IEEE International Conference on Advanced Learning Technologies, pp. 788-792, Kaohsiung, Taiwan.

Princeton University (2006). WORDNET - A Lexical Database for the English Language. URL: http://wordnet.princeton.edu/

Rodríguez-Artacho, M. \& Maíllo, M. F. V. (2004). Modeling Educational Content: The Cognitive Approach of the PALO Language. Educational Technology E Society, Vol. 7, No. 3, pp. 124-137

Schmidt, H. G. (1983). Problem-Based Learning: Problem and Definition. Medical Education, Vol. 17, pp. 11-16

Schmietendorf, A. \& Mencke, S. (2008). Evaluation Aspects for the Sustainable Integration of e-Learning in the Domain of Software Engineering (In German). Proceedings of the 18th International Workshop in Software Measurement in conjunction with the Mensura and the DASMA Software Metric Kongress, Lecture Notes in Computer Science, Vol. 5338. Munich, Germany. Springer Verlag

Simon, B. (2002). Do E-learning Standards Meet their Challanges? Proceedings of the Workshop Standardisation in E-learning (In German), pp. 14-22, Frankfurt/Main, Germany.

Sowa, J. F. (2000). Knowledge Representation: Logical, Philosophical, and Computational Foundations. Brooks Cole Publishing Co.

Süss, C. (2000). Adaptive Knowledge Management: A Meta-Modeling Approach and its Binding to XML. Proceedings, 12th GI-Workshop Grundlagen von Datenbanken

Tallon, P. P. \& Scannell, R. (2007). Information Life Cycle Management. Commununications of the ACM, Vol. 50, No. 11, pp. 65-69

Trevena, L. J. (2007). Problem-Based Learning in Public Health Workforce Training: A Discussion of Educational Principles and Evidence. N S W Public Health Bulletin, Vol. 18, No. 1-2, pp. 4-8

Ullrich, C. (2004). Description of an Instructional Ontology and its Application in Web Services for Education. Proceedings of Workshop on Applications of Semantic Web Technologies for E-learning (SW-EL'04), pp. 17-23, Hiroshima, Japan

Vornholt, S. \& Mencke, S. (2008). Ontologies for the Virtual Engineering Process. Proceedings of the 11. IFF-Wissenschaftstage, Magdeburg, Germany

World Wide Web Consortium (W3C) (2004a). Resource Description Framework (RDF) Primer. Link: http://www.w3.org/RDF-primer/

World Wide Web Consortium (W3C) (2004d). Web Ontology Language (OWL). Link: http:// www. w3.org/2004/OWL/

Zhang, H. (2009). Tool for the Creation of Ontology-Based E-learning Courses. Master's Thesis. Otto-von-Guericke University Magdeburg, Germany 


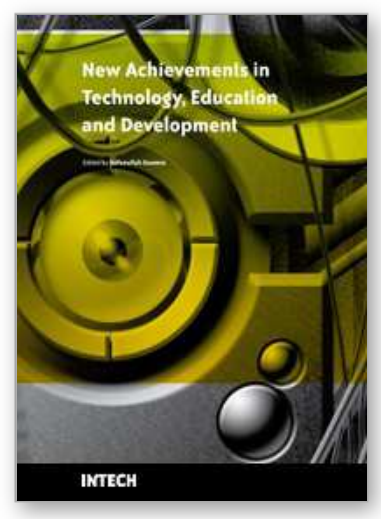

\author{
New Achievements in Technology Education and Development \\ Edited by Safeeullah Soomro
}

ISBN 978-953-307-066-7

Hard cover, 460 pages

Publisher InTech

Published online 01, March, 2010

Published in print edition March, 2010

Since many decades Education Science and Technology has an achieved tremendous recognition and has been applied to variety of disciplines, mainly Curriculum development, methodology to develop e-learning systems and education management. Many efforts have been taken to improve knowledge of students, researchers, educationists in the field of computer science and engineering. Still many problems to increase their knowledge on daily basis so this book provides newly innovations and ideas in the field of computer science and engineering to face the new challenges of current and future centuries. Basically this book open platform for creative discussion for future and current technologies to adapt new challenges in education sector at different levels which are essential to understand for the students, researchers, academic personals and industry related people to enhance their capabilities to capture new ideas and provides valuable contribution to an international community.

\title{
How to reference
}

In order to correctly reference this scholarly work, feel free to copy and paste the following:

Steffen Mencke and Reiner Dumke (2010). Semantics-Enhanced E-learning Courses, New Achievements in Technology Education and Development, Safeeullah Soomro (Ed.), ISBN: 978-953-307-066-7, InTech, Available from: http://www.intechopen.com/books/new-achievements-in-technology-education-anddevelopment/semantics-enhanced-e-learning-courses

\section{INTECH}

open science | open minds

\author{
InTech Europe \\ University Campus STeP Ri \\ Slavka Krautzeka 83/A \\ 51000 Rijeka, Croatia \\ Phone: +385 (51) 770447 \\ Fax: +385 (51) 686166 \\ www.intechopen.com
}

\author{
InTech China \\ Unit 405, Office Block, Hotel Equatorial Shanghai \\ No.65, Yan An Road (West), Shanghai, 200040, China \\ 中国上海市延安西路65号上海国际贵都大饭店办公楼 405 单元 \\ Phone: +86-21-62489820 \\ Fax: $+86-21-62489821$
}


(C) 2010 The Author(s). Licensee IntechOpen. This chapter is distributed under the terms of the Creative Commons Attribution-NonCommercialShareAlike-3.0 License, which permits use, distribution and reproduction for non-commercial purposes, provided the original is properly cited and derivative works building on this content are distributed under the same license. 